\title{
ESTUDIOS
}

\section{Del sacrificio público a la experiencia privada: Metaforología del espacio en las upanișad}

\section{From public sacrifice to private experience: Metaphorology of space in the upanișad}

\author{
JUAN ARNAU \\ Consejo Superior de Investigaciones Científicas
}

Recibido: 18-7-2012

Aprobado definitivamente: $20-11-2012$

\section{RESUMEN}

El artículo analiza las concepciones del espacio y del tiempo en el periodo védico tardío, utilizando como fuentes primarias el antiguo corpus de textos sánscritos conocido como upanișad. Para ello se estudian las diversas cosmogonías y las diferentes formas de legitimación de una gradual transformación del sacrificio público (dominante en la época védica temprana, caracterizada por las colecciones de himnos y una literatura de comentarios de carácter litúrgico) a la experiencia privada de la meditación y la especulación filosófica (característica de tradiciones ascéticas).

\author{
PALABRAS CLAVE \\ COSMOGONÍA, UPANIȘAD, ESPACIO, TIEMPO
}

(C) Contrastes. Revista Internacional de Filosofía, vol. XVIII (2013), pp. 249-264. ISSN: 1136-4076

Licenciatura de Filosofía, Universidad de Málaga, Facultad de Filosofía y Letras

Campus de Teatinos, E-29071 Málaga (España) 


\begin{abstract}
In this article we analyse the conceptions of space and time in the later Vedic period, using as primary sources the old corpus of Sanskrit texts known as Upanișad. For this purpose we study the various cosmogonies and different forms of legitimation of a gradual transformation of the public sacrifice (dominant in early Vedic times, characterized by collections of hymns and a literature of comments of a liturgical nature) to the private meditation experience and philosophical speculation (characteristic of ascetic traditions).
\end{abstract}

KEYWORDS

COSMOGONY, UPANIȘAD, SPACE, TIME

\title{
I. PReliminares
}

A PESAR DE LAS INSINUACIONES Y METÁFORAS de las colecciones de himnos (samhitā) y de los textos litúrgicos (brāhmaṇa), puede decirse que el despertar de la especulación cosmológica en India surge de las tradiciones del bosque (upanișad, aranyaka). ${ }^{1}$ Los textos que han sobrevivido de estas tradiciones orales siguen ocupando un lugar de excelencia en el pensamiento hindú y todavía son objeto de comentarios en la filosofía contemporánea. No sabemos quienes fueron sus autores, algunos de los más antiguos (Bṛhadāraṇyaka, Chāndogya y Kaușitaki) son seguramente antologías de diversa procedencia. En ellos se

1 Abreviaturas: Aitareya-brāhmana, AV: Atharva-veda, BU: Brhadāranyaka-upanișad, CU: Chāndogya-upanișad, IU: Isa-upanișad, KB: Kaușittaki-brāhmana, KU: Kața-upani-ad, MB: Mahābhārata, MtU: Maittrāyañ̄ya-upanișad, MU: Mundaka-upanișad, RV: Rgveda, ŚB: Śatapatha-brāhmaṇa, ŚU: Śvetāśvatara-upanișad, TU: Taittirīya-upanișad.

De entre las ediciones críticas de las upanișad cabe mencionar la colección realizada por los pandits de ĀNANDĀŚRAMA, publicadas en las Sanskrit Series de Poona: İ́sakenokatopanișadah (1915), Aitareyopanișad (1980), Muṇdakopaniṣad (1935), Taittirīyopanișad (1977), Praśnopanișad. (1980) y Kenopanișad (1980). Otras ediciones y traducciones incluyen: BUITENEN, J. A. B. (ed. y trad.) 1962. Maittrāyañ̄ya-upanișad. The Hague: Mouton. GAMBHİRĀNANDA (ed. y trad.). 1983. Chāndogya Upanișad. Calcutta: Advaita Ashrama. DE PALMA, D. (trad.) 1995. Upanișads, Madrid: Ediciones Siruela. HUME, R. E. (trad.) 1923. The Thirteen Principal Upanishads. London: Oxford University Press. MADHAVANANDA (ed. y trad.). 1982. The Brhadāranyaka Upanișad. Calcutta: Advaita Ashrama. NIKHILANANDA (trad.). 1964. The Upanishads. New York: Harper and Row. OLIVELLE, P. 1998. The Early Upanisads. Annotated Text and Translation. New York: Oxford University Press. Especialmente recomendable, por su calidad y erudición, es esta última edición de Patrick Olivelle. 
recogen las enseñanzas de Yājñavalkya, Uddālaka y Janaka en forma de diálogos, instrucciones o debates. Entre estos maestros se encuentran algunas mujeres, como Gārgī y Maitreȳî, que participan activamente en disputas teológicas y filosóficas.

La palabra sánscrita upaniṣad significa «correspondencia», «enlace»y también «equivalencia». De ahí que nos refiramos a este corpus de textos como Literatura de las correspondencias. Dicho enlace hacía posible el ritual y lo justificaba, sirviendo de presupuesto teúrgico a su eficacia, mientras que las correspondencias darían lugar a las imágenes y conceptos del pensamiento especulativo. Según esta literatura los diferentes elementos de lo existente, prima facie independientes, guardan ciertos vínculos secretos que la ciencia de las upanișad irá desvelando y cartografiando. Un arte del descubrimiento y la detección de las afinidades que constituyen la urdimbre del mundo. Y dado que su sabiduría consistirá en profundizar en dichas afinidades y transmitirlas, el término upanișad acabará significando también «doctrina secreta» $\mathrm{y}$ «rito».

Las upanișad fueron editadas, memorizadas y conservadas oralmente por las distintas ramas o escuelas de transmisión y, en el caso de las más antiguas (Brhadāranyaka y Chāndogya), podemos situarlas antes del nacimiento de Buda. Uno de los aspectos más interesantes de estos textos (que se reproducirá luego en el mahāyāna) es que la ética no es un fin en sí misma, sino sólo una vía de acceso (una propedéutica) a estados de conciencia liberados de las ataduras de lo contingente.

\section{GENEALOGÍA DE UNA TRANSFORMACIÓN}

Las tres grandes preocupaciones del pensamiento védico fueron el ritual, la cosmología y la condición humana. El ritual establecía la conexión, mediante ceremonias, conjuros, oraciones y cánticos, entre lo cósmico y lo humano. Su lógica no establecía distinción alguna entre los dioses y las energías del cosmos, de modo que cosmología y mitología se fundían en una única ciencia, encargada de encontrar las conexiones entre estos tres ámbitos, descifrando los signos que los vinculan y que permitirán, manipulando uno, alterar el otro. Esto se hacía fundamentalmente a través del ritual, pero también a través del cuerpo como imagen reflejada del cosmos. Se va abriendo paso así la figura del asceta, como laboratorio fisiológico que utiliza el propio cuerpo para las operaciones que antes se realizaban en el altar. De modo que no resultaría arriesgado decir que el universo ritual de los samhitā y brāhmaṇa, que ambiciona la manipulación de las energías cósmicas, da paso, a otro tipo de ceremonia, corporal y especulativa, que va tomando forma en las upanișad..$^{2}$ De la especulación centrada en

2 Los himnos (samhitā) védicos constituyen el corpus de textos más antiguo de la civilización india. La palabra veda significa «conocimiento» y generalmente se entiende por literatura 
el ritual pasamos a la especulación centrada en la transmisión: una instrucción o enseñanza esotérica que pasa de maestro a discípulo. Aunque no faltan las especulaciones rituales y cosmológicas, puede decirse que el tema central de las upanișad es lo humano: la constitución del cuerpo, sus energías vitales y sus facultades cognitivas. Las relaciones entre el propio organismo, incluida la mente y el lenguaje, y ese otro organismo que es el cosmos.

Algunas estrofas del Rgveda mencionaban una entidad denominada brahman que en la literatura de las correspondencias se convertirá en uno de los ejes centrales de la especulación filosófica. ${ }^{3}$ El término brahman significó en el brahmanismo antiguo el poder del ritual, «sin que hubiera nada más antiguo o más brillante», como dice un viejo texto, pero con el tiempo llegaría a convertirse, en manos de los filósofos, en la esencia del universo, en el verdadero Ser que anima todo fenómeno y toda apariencia. Para algunos -dice la Brhadāranyakael brahman es el habla, para otros el aliento vital, el ojo, la mente y el corazón, pero en realidad, dice el sabio, es el sostén último de todos estos fenómenos. El brahman no es sólo la esencia del ritual del mundo, sino que constituye también la esencia del Sí (ātman) en el que moran todos los seres, lo verdadero en la persona más allá de su constitución aparente.

Ciertos pasajes asocian el brahman con el poder inherente a la entonación de los salmos, aunque su significado se amplia frecuentemente al de una energía cósmica inherente a todo lo creado, que impregna el espacio y el tiempo e impulsa el desarrollo de todos los fenómenos y formas de existencia. La afinidad entre brahman y el lenguaje sagrado confirió a la pronunciación de las sílabas un carácter teúrgico y las letras del alfabeto sánscrito pasaron a personificar diferentes aspectos del cosmos. Algunos himnos védicos conciben el universo primordial como sonido puro. Antes de la luz y la materia, el sonido habitaba y configuraba el espacio, se hacía sitio. El sonido precursor de la luz, la música madre de la astronomía y la biología: estamos hechos de armonías, por eso la música nos conmueve. ¿No habría de ser entonces oral esta tradición de pensamiento? ¿No habría de descansar en dicha transmisión sonora la esencia de su entendimiento del mundo? El habla $(v \bar{a} c)$ no es meramente un principio de

védica a cuatro colecciones de himnos diferentes: Rgveda: estrofas de alabanza y celebración, Yajurveda: fórmulas rituales, Sāmaveda: cantos, y Atharvaveda: taumaturgia. A estas colecciones, en su mayoría en verso, hay que añadir sus comentarios en prosa: la literatura litúrgica de los brāhmaṇa y otras colecciones de textos más filosóficos y especulativos: āranyaka y upaniṣad que se analizan en el presente artículo.

3 Las principales ediciones del Rgveda son: M. Müller, Rig-Veda-Sanhita, 6 vols., Londres, 1849-1874. Th. Aufrecht, Dye Hymnen des Rigveda, 2 vols., Berlín, 1861-1863. N. S. Sontakke y C. G. Kashikar, Rgveda-Samhitā, 4 vols., Puna, 1933-1946. Lahore, 1939. L. Sarup, RgvedaSaṃhitā with Mādhava's commentary, Lahore, 1939. V. Bandhu, Rgveda, 8 vols., Hoshiarpur, 1963-1966. 
inteligibilidad, sino el proceso mediante el cual el mundo se hace inteligible (y en este sentido es pariente cercano del logos griego). Y se dirá que $v \bar{a} c$ es al mismo tiempo el hablante, la palabra, lo nombrado y el receptor del significado. Siendo además la herramienta indispensable que permite conocer los textos de la tradición, los antiguos relatos y ritos y las diferentes ciencias. Sin ella no podría distinguirse el bien del mal, la verdad de la falsedad, lo justo (dharma) de lo injusto (adharma). ${ }^{4}$

El poder del habla en la literatura védica, la naturaleza íntima del lenguaje, es una diosa que hace sabios a los hombres. Un medio a través del cual se manifiesta la verdad, siendo esa misma verdad poder. La vía entre el Uno (brahman) y la diversidad del mundo se establece mediante la sílaba $\mathrm{Om}$. Del mismo modo que todas las hojas se juntan en el tallo, todos los sonidos, todas las palabras, se funden en esta sílaba sagrada. $V \bar{a} c$ coincide con el logos del evangelio joánico en su condición de «palabra del principio», de estructuración cósmica plena de sentido. De ahí que pueda ser, al mismo tiempo, el hablante, la palabra que nombra, el significado de la palabra, el objeto nombrado y el receptor del significado. La Kena-upanișad se iniciará preguntando: «iImpulsada por qué la mente se cierne sobre su objeto? ¿Dirigido por quién brota el primer respiro? ¿Incitados por quién pronunciamos estas palabras?» Y la Chāndogya añade: «El habla es la esencia del hombre, el verso (védico) es la esencia del habla [...] El habla y el aire vital forman una pareja, cuando se acoplan en la sílaba om, los dos satisfacen su mutuo deseo». 5

Esa correspondencia entre la estructura del mundo y la estructura de la mente, que se sirve del lenguaje para diversificar y unificar, se encuentra relacionada con otra idea de importancia cosmogónica: la identificación del sacrificio con el sacrificador y la víctima. Ya en los himnos tardíos del Rgveda, como hemos visto, se fue afianzando la idea de que el universo había surgido de un sacrificio primordial. Hemos mencionado ya el himno noventa del décimo mandala, en el que Prajāpati se presenta como el hombre primordial (purușa) que, mediante su autosacrificio, da lugar al proceso creativo y diversificador del mundo. De ese sacrificio primordial surge el tiempo, de él los seres vivos y con ellos los ritos y los metros poéticos que harán posible la reintegración a la unidad original. Encontramos aquí una de las primeras manifestaciones del vínculo secreto que ata la creación del mundo con la liberación del individuo. La celebración periódica del ritual del sacrificio es al mismo tiempo la regeneración y la revitalización de las energías cósmicas, constituyendo la oportunidad para la reintegración a la unidad original. 
Con la idea de la regeneración periódica del tiempo y la idea de un regreso cíclico de todas las formas a un origen indiviso, se contrarresta la persistente erosión de la existencia, el cansancio metafísico (cualquier tiempo pasado fue mejor) que en su devenir va agotando la sustancia ontológica. Un modo de recuperar el entusiasmo de lo potencial frente a la melancolía de lo realizado (solo lo que no ha ocurrido no envejece). La necesidad de regenerar periódicamente el tiempo nos recuerda algo olvidado por la modernidad filosófica. El tiempo, como el hombre, se desgasta, como la madera, se pudre, como el metal, se oxida. El tiempo tiene una textura, no es ni homogéneo ni estático, no es inmune a los avatares de su discurrir. Para contrarrestar esta decadencia, para devolver al tiempo su frescura original, el ritual opera su renovación, iniciando una nueva era (un pasaje cósmico o social) que inaugura tras su ejecución. Pero este simbolismo del sacrificio será llevado mucho más lejos y cada acto del ritual pasará a identificarse con algún aspecto específico del cosmos. Dicha identificación simbólica alcanzará su punto culminante en las minuciosas correspondencias entre el Todo y las Partes desarrolladas en las upanișad.

Este es un buen ejemplo de cómo, en los estadios más antiguos de la especulación filosófica, las cuestiones más acuciantes sobre qué es (el universo, la vida, el amor), no apuntan a los componentes físicos del mundo, sino que se dirigen a elementos simbólicos. Dichos elementos simbólicos aparecen en el universo con la mediación de lo humano, que los construye y preserva socialmente. Podemos acceder a la naturaleza de dichas entidades precisamente porque son lo más humano que existe, mientras que probablemente nunca sepamos qué es la materia. El ritual fue un medio antiguo de establecer la certeza simbólica, de fortalecerla y protegerla, $y$, desde esta perspectiva, fue una de las primeras manifestaciones en la construcción de significados.

\section{DEL SACRIFICIO PÚBLICO A LA EXPERIENCIA PRIVADA}

La prominente figura del sacerdote en las colecciones de himnos (samhitā) y en la literatura litúrgica (brāhmaṇa) va dando paso, gradualmente, a la figura del asceta. Esa transición se opera en las upanișad. Las experiencias con uno mismo adquieren el prestigio que antes tenían las experiencias en el altar. Pero el prestigio del renunciante, como sucede a menudo en India, no era nuevo. Ya en el Rgveda se habla de «los silenciosos que, llevando el viento como cinturón, recorren los caminos de las aves y de los dioses embriagados por su silencio. ${ }^{6}$ $\mathrm{Y}$ es precisamente en uno de los himnos de este mismo libro donde se aventura la idea de que el universo surgió del ardor (tapas) incubado en la práctica ascética, abriendo paso la idea del purușa como yogui cósmico. ${ }^{7}$ Otro himno 
del mismo libro corrobora esta idea. ${ }^{8}$ Viśvakarman, el hacedor del mundo, es al mismo tiempo el que ejecuta el sacrificio y su víctima. ${ }^{9}$ Esa unidad de destino, muy característica del pensamiento sacrificial, dará paso a la transición entre una experiencia pública, representada por el ritual, y una experiencia privada, representada por la mente del asceta. La teología sigue sin embargo subordinada a la cosmología (los dioses se encuentran supeditados a los ciclos de evolución e involución del cosmos, mueren con cada disolución y surgen nuevos con cada recreación), pero esa cosmología irá derivando hacia una cosmología donde experiencia interior irá apoderándose del prestigio del altar. Mientras que en la cosmología ritual el objetivo era apoderarse de las fuentes de la energía primordial, la cosmología mental buscará denodadamente su propia vía de liberación del entramado cósmico.

La Bṛadāranyaka-upanișad confirma esta tendencia. Se atribuye la creación a un acto de conciencia del $\bar{a} t m a n .{ }^{10}$ Una forma humana primordial (purușa), era lo único que existía en el origen. Miró a su alrededor y no vio a nadie. Sintió miedo y al mismo tiempo se preguntó de qué habría de tener miedo, después de todo, uno siempre tiene miedo de algo. No encontrando placer alguno, pues nada podía compartir, surgió en él deseo de compañía. Dividió su cuerpo en dos, dando lugar al hombre (pati) y a la mujer (patñ̄), y de su amorosa unión surgieron el resto de las criaturas. La idea de la creación a partir de un acto sexual cósmico desempeñaría un importante papel en el pensamiento posterior. Otros pasajes explican la creación a partir de los elementos, postulando como origen el agua, el fuego o el viento. También se sugiere que el mundo no se desarrolló a partir de fuerzas externas al propio mundo, sino mediante un proceso interno (svabhāva) de maduración. O bien lo atribuyen al tiempo (kāla), asociado con la idea del destino (niyati), o al espacio $(\bar{a} k \bar{a} s ́ a)$. Las explicaciones son numerosas y no siempre coherentes entre sí.

Se duda en este mundo de la suerte del difunto, dice la Kațha-upanișad, pero el mortal madura como la cosecha. Y como la cosecha vuelve de nuevo a nacer. ${ }^{11}$ El fuego que lleva al paraíso -explica la Muerte a Naciketas- es el medio para alcanzar el mundo infinito y su fundamento y se encuentra asentado en la caverna del corazón. ${ }^{12}$ Pero hay un deseo más excelso que el de conocer el fuego del sacrificio original que lleva al paraíso, ese deseo, que alcanza lo perdurable con materiales perecederos, es el conocimiento del ätman y del brahman, que se encuentra más allá de la felicidad condicionada del paraíso. El

$8 R V 10.81$.

9 «Si el que golpea cree que mata y el golpeado se tiene por muerto, ninguno de los dos conoce nada». (KU 2.19), Kuiper (1983).

$10 B U$ 1. 4. Edición sánscrita de Olivelle (1998).

$11 K U 1.20,1.6$.

$12 K U 1.14$. 
sabio medita en el adhyātmayoga, la recolección de la mente, apartada de los objetos de los sentidos y dirigida hacia el Sí (ātman), que no debe confundirse con el yo (aham), que tiene la misma condición fenoménica que el sonido o el color, tan empírico que puede degenerar, en el giro de las existencias, hasta en lo inorgánico. ${ }^{13}$ Se trata pues de conocer el ātman en el yo, y no el ätman del yo, agazapado en la caverna del corazón, morador del abismo y primordial. ${ }^{14} \mathrm{Se}$ deshecha el yo, cargado de atributos, y se apropia de lo sutil, deleitándose en la fuente de todo deleite, morada abierta al brahman. ${ }^{15}$ Y se dirá, en otros lugares, que conocer el brahman es ser brahman pues, en definitiva, es brahman quien se conoce y quien conoce en nosotros, idea que, como veremos, llevará hasta sus últimas consecuencias la filosofía sāṃkhya.

Esa es la meta que todas las ascesis proclaman. Es la sílaba om, el sonido primordial, el soporte supremo, la consciencia que ni nace ni muere, que no surge de otro ser ni en otra cosa deviene, eterna y primordial. ${ }^{16}$ Asentado en el corazón de las criaturas, sutil entre lo sutil, incorpóreo entre lo corpóreo, estable en lo inestable. ${ }^{17} \mathrm{Y}$ surge aquí la idea de la gracia, pues no se puede conocer ese àtman ni mediante la enseñanza recibida ni mediante el entendimiento. Sólo puede conocerlo aquel a quien él mismo escoge. A ese, el ätman se le revela en su propio cuerpo. ${ }^{18}$

Los sabios lo consideran el sujeto de la experiencia,${ }^{19}$ no siendo accesible a la mente dispersa sino sólo a la recogida. ${ }^{20}$ Sólo aquellos capaces de vislumbrar lo sutil pueden reconocerlo en su penetrante intelecto. ${ }^{21}$ Camino difícil de transitar, como el filo cortante de la navaja. ${ }^{22}$ Quien lo conoce no vuelve a nacer jamás, liberándose de las fauces de la muerte, mientras que quien lo ignora renace indefinidamente en el ciclo de las transmigraciones. ${ }^{23}$

Y se lo compara con el fuego, que mora oculto en dos varillas de madera, con el embrión que late en la mujer preñada. En él se encuentran trabados todos

13 Fatone $(1972,200)$ cita un pasaje de la Kațopaniṣad (KU 5, 6-7): «Después de la muerte, según sus obras y conocimientos, unos vuelven al cuerpo como seres orgánicos, y otros van a la materia inorgánica». De nuevo se da por sentada la continuidad entre lo vivo y consciente y lo inerte e inactivo.

$14 K U 2.12$.

$15 K U 2.13$.

$16 K U 2.15-18$.

$17 K U 2.22$.

$18 K U 2.23$.

$19 K U 3.4$

$20 K U 2.24 ; 3.5$.

$21 K U 3.12$.

$22 K U 3.14$.

$23 K U 3.7-8$. 
los dioses, como los radios al eje de una rueda. ${ }^{24}$ Lo que hay aquí es lo que hay más allá. En verdad la diversidad del mundo es aparente. Quien sólo ve diversidad, renace indefinidamente. ${ }^{25}$

El que existe por sí mismo, perforó hacia afuera las aperturas de los sentidos. Por ellos el yo ( $\mathrm{aham}$ ) ve los objetos externos, y no el principio inmanente. Sólo al invertir la mirada, puede contemplarse el àtman interno. ${ }^{26}$ Pero es el Uno, el que primero nació del ardor ascético (tapas), abrigado en la caverna del corazón, el que disfruta de todas las experiencias conscientes, el que, mediante los seres, contempla la diversidad del mundo. Infinidad modeladora de los dioses y los seres vivos, que, mediante ellos sale de sí y mira al exterior. ${ }^{27}$

Las ideas aquí contenidas tendrán un largo recorrido en el pensamiento filosófico. Los seres son los sentidos del principio original. Por sus once puertas, ve, oye, siente el que no ha nacido, la diversidad de lo natural. ${ }^{28}$ Ese huésped vive en una ciudadela de once puertas: el cuerpo humano, con sus once orificios: oculares, auditivos, nasales, la boca, el ano y el órgano genital, el ombligo y la sutura craneal. ${ }^{29}$ Todas las potencias o facultades anímicas superiores le sirven de regocijo. ${ }^{30} \mathrm{Y}$ aunque parezca que se vive del aire inhalado y del aire exhalado, los seres viven de otra cosa.

El sāṃkhya profundizará en esta idea: los seres son las ventanas mediante las cuales el purușa se abre y atiende a la diversidad del mundo. El purușa permanece despierto mientras los seres duermen, moldea continuamente todos los deseos, late en cada una de las formas, es aquel que diversifica la Única forma. En él descansan todos los mundos, nada lo trasciende. ${ }^{31}$ Pero no le afecta el dolor del mundo, ya que se encuentra fuera de su alcance. ${ }^{32}$ Es lo eterno en lo transitorio, es la consciencia en los seres, siendo Uno, satisface incontables deseos. ${ }^{33}$ Brilla con luz propia y, en los seres, con luz reflejada. ${ }^{34}$ Se ve a sí mismo en la mente como en un espejo, en el mundo de los antepasados como en un sueño, en el mundo fenoménico mediante contrastes. ${ }^{35} \mathrm{Y}$ se manifiesta

$24 K U 4.8-9$.

$25 K U 4.10-11$

$26 K U 4.1$.

$27 K U$ 4.6-7.

$28 K U 5.1$.

29 Algunas listas citan nueve orificios, al omitir los dos últimos Pujol e Ilárraz (2004, 114).

$30 \quad K U 5.3$.

$31 K U 5.8 ; 5.12$.

$32 K U 5.11$

$33 K U 5.13$

$34 K U$ 5.14-15.

$35 K U 6.5$. 
con diferentes grados de claridad. En el intelecto purificado es donde se refleja con mayor nitidez, como una imagen en un espejo. Pero también se refleja en el mundo de los antepasados, en la confusión propia de los sueños, y en el mundo de la experiencia común, con sus luces y sus sombras. Siendo conocido sólo en aquel que afirma su existencia, pues sólo en el ser consciente puede vivir (en el sentido que damos normalmente a esta palabra). ${ }^{36}$

\section{LA NUEVA CONCEPCIÓN DEL ESPACIO}

Los ejemplos más antiguos de lo que podría llamarse una «cosmogonía del espacio» los encontramos en la Chāndogya-upanișad. Aquí se concibe el espacio como un poder diferenciador donde se manifiestan el nombre y la forma (näma-rūpa) y que constituye la semilla del mundo. ${ }^{37}$ «Del espacio surgen todos los seres y a él finalmente regresan, pues existe en verdad antes que ellos y en él encuentran su fin». ${ }^{38} \mathrm{Y}$ «lo que la gente llama brahman no es sino este espacio fuera de la persona. Y ese espacio exterior no es sino el espacio dentro de la persona». En este sentido, el espacio ( $\bar{a} k \bar{a} s a)$ sirve de metáfora para el fundamento (brahman) y su reflejo diversificado en los seres (ätman). «Este àtman mío, que descansa en lo profundo del corazón, esta hecho de mente. Las funciones vitales ( $\operatorname{prāna}$ ) son su forma física, luminosa es su apariencia, real su intención. El espacio es su esencia (ătman), que contiene todas las acciones, todos los deseos, todos los olores y todos los gustos. El espacio abarca todo el mundo, ni habla ni presta atención». ${ }^{39}$ Pero, «ese a tman que habita en lo profundo del corazón es más pequeño que un grano de arroz, más pequeño que una semilla de mostaza, más pequeño que un grano de mijo; y sin embargo es más grande que la Tierra, más grande que el espacio intermedio, más grande que los cielos, más grande que todos los mundos juntos [...] Tan vasto como el espacio que nos rodea es el espacio del corazón». ${ }^{40}$ «Este ātman es brahman y tras la muerte se convertirá en brahman». ${ }^{41}$ Más adelante se dirá que en el ámbito del cuerpo uno debería pensar que el brahman es la mente, mientras que en el ámbito de lo divino, brahman se asocia con el espacio. ${ }^{42}$ También el espacio se asocia al brahman por ser aquello que comparten todos los seres, por ser ámbito común del enriquecimiento humano, ${ }^{43}$ de la vida misma mediante el proceso de la respiración, por ser aquello donde se produce la apariencia visible de las cosas,

$36 K U 6.12$.

37 CU 8.14.1.

$38 C U$ 1.9.1.

$39 C U 3 \cdot 12.7-8$.

40 CU 8.1.3.

$41 C U 3.14 .2-4$.

42 CU 3.18.1.

43 CU 5.15.1. 
y ser su morada incondicional. ${ }^{44}$ La identificación de brahman con el espacio se repite en otros lugares de la Literatura de las correspondencias (upanișad), como en la tardía Maittrāyañìya, donde se reitera que el universo es creado a partir de $\bar{a} k \bar{a} s ́ a$ y a él regresa. ${ }^{45}$

\section{REABSORCIÓN Y LIBERACIÓN}

La idea de que el mundo se encuentra sujeto a recreaciones y disoluciones periódicas y la contraposición entre dicho proceso cósmico y la vida del individuo, entendida como aspiración a la liberación, va tomando cuerpo a lo largo de esta fascinante literatura de las correspondencias. Escapar a los ciclos del tiempo y reintegrarse en la Unidad Original (reabsorción en un estado indiviso previo a la creación) es una aspiración que aparecerá con frecuencia en las grandes épicas de la época clásica, y la secuencia recreación-preservación-disolución del cosmos será asociada a los tres grandes dioses del panteón hindú: BrahmāViṣnu-Ṣiva. Sin embargo, es posible la liberación sin que sea necesario que el mundo creado alcance su disolución. Algunos textos sugieren que los seres que han logrado la liberación ( $m o k s ̦ a$ ), permanecen en mundos superiores a la espera de la disolución del cosmos, momento en el cual se reabsorben en el Fundamento (brahman). Esta idea de la reabsorción del mundo creado se encuentra ya en las upanișad más antiguas. El pasaje mencionado de la Chāndogya que se pregunta por el destino de los diferentes elementos y del mundo, alude al espacio (cuyo fundamento es el sonido primordial) como la fuente de la que surgen todos los seres y el depósito donde serán finalmente reabsorbidos. ${ }^{46}$

La Taittirīya-upaniṣad confirma esta idea. Varuṇa alecciona a su hijo Bhṛu: «El alimento, el aire vital y la vista son brahman. El oído, la mente y el habla son brahman. Brahman es aquello por lo que los seres nacen, aquello por lo que viven y aquello a lo que se reintegran al morir. ¡Ve y percíbelo tú mismo!»». ${ }^{47}$ Bhrgu se marcha y practica el ascetismo en busca de brahman. Comprende que el alimento es brahman pues de él nacen todos los seres, por él viven y a él se reintegran al morir. Practicando el ascetismo comprende que lo mismo puede decirse del aire vital y de la mente, y que el conocimiento de brahman supone la dicha (änanda) y que todos los seres nacen de esta dicha. «Y el que esto conoce, al abandonar el mundo, alcanza el ātman que es alimento, el ātman que es aire vital, el àtman que es mente, el àtman que es percepción; y finalmente el àtman que es pura dicha. Y viaja a través de los mundos, comiendo a su antojo 
y asumiendo las formas que desea, cantando un salmo del Sāmaveda». ${ }^{48}$ Con dicho canto se identifica a este viajero sideral con el ritmo cósmico (ślokakśt), creador de la diversificación y reintegración de los elementos, y con el primogénito del orden cósmico $(r t a)$, nacido antes que los dioses. ${ }^{49}$

También la Śvetāśvatara-upaniṣad hace alusión a la naturaleza cíclica del tiempo. Se trata de una invocación que solicita lucidez a «Aquel que, incoloro, ha creado todos los colores, Aquel del que surge el universo y en el que se disuelve». ${ }^{50}$ La Muṇdaka-upanișad recurre a la metáfora del fuego primordial y se inicia diciendo: «Como del fuego llameante saltan innumerable chispas semejantes en naturaleza al fuego, del mismo modo, querido amigo, del imperecedero surgen las diversas cosas y a él regresan». ${ }^{51}$

Aunque un pasaje de la Mundaka asocia la disolución y recreación del mundo con el sueño y el despertar, ${ }^{52}$ diciendo que Brahmā hace que el mundo despierte (bodhayati), no puede afirmarse que la Literatura de las correspondencias aluda explícitamente a un carácter recurrente de todo el proceso. Sobre esta cuestión no hay acuerdo entre los expertos. Para Van Buitenen, la única posible alusión a una repetida recreación y disolución del cosmos es una interpolación añadida a Maittrāanaṇ̄ya-upanișad, H. Jacobi y M. Eliade consideran que esa idea es muy antigua y que puede inferirse de un pasaje del Atharvaveda, Keith rechaza esta hipótesis. ${ }^{53}$ Sea como fuere, la idea de una recreación y disolución cósmica repetida ad infinitum, se consolidará en la cosmología sāṃkhya y budista, así como en las concepciones mitológicas de los purāna.

\section{LA AVENTURA DEL FUNDAMENTO}

Recapitulemos. La presencia y formación de los fenómenos y las cosas, su evolución en el espacio y en el tiempo, se presentan en el periodo védico como una limitación del fundamento (miedo a la soledad del purușa, según $B U$ 1.4) y como resultado de una acumulación de ardor ascético (tapas) que dará lugar a la diversidad de lo fenoménico. Dicha autolimitación supone la acotación de un lugar y de ella surge el espacio $(a k \bar{a} s a)$ que, como hemos visto, algunas upanișad consideran el origen de todas las cosas y destino al que habrán de regresar. Implícita en esa limitación, parece haber una exigencia de superación: el límite es dado con el fin de superarlo. De este modo el fundamento halla

$48 \quad T U 3.10 .5$

$49 T U$ 3.10.6.

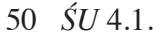

$51 M U 2.1 .1$.

$52 \mathrm{MtU} 6.17$.

53 Concretamente $A V$ 10.8.39Đ40. H. Jacobi: «Ages of the world (Indian)» en Hastings (ed.), Encyclopaedia of Religion and Ethics $(1913,201)$. V. Eliade $(1997,113)$ y Keith $(1925$, 82). 
un estímulo, diversificándose en innumerables identidades incompletas. Tras un primer momento de negación (autolimitación del Uno), surge un segundo momento de afirmación (la presencia de los seres) y de superación (su libertad posible). Estas tres fases constituyen el curso del tiempo en la cosmovisión védica. Siendo una evolución de la conciencia, el tiempo se concibe como (1) autolimitado, (2) escindido y diversificado y (3) destinado a regresar a la unidad original. En este sentido puede decirse que la contingencia de lo finito gana un horizonte. La limitación esencial de los seres se asocia entonces con la idea de lo incompleto o inacabado y, en el nivel soteriológico, plantea a la infinitud finita del ser consciente la tarea de asumir el desafío del fundamento.

Estas son, a grandes rasgos, las diferentes concepciones del tiempo en la época védica, que entienden la liberación (mokșa) como el objetivo supremo de la vida consciente y su más acuciante responsabilidad (la libertad es aquí la realización de una necesidad superior). Pero queda todavía una pregunta por contestar: ¿Por qué se entrega el espíritu del mundo, el Uno, a la limitación? ¿Cómo es posible que el fundamento (brahman) derive en lo contingente? Como hemos visto, algunos pasajes sugieren que el fundamento prefiere la fragilidad a la soledad: el brahman se identifica con la diversidad limitada (ātman) y se aventura con ella. Una de las metáforas que dan cuenta de dicha asociación es la de la sal en el agua. Una vez disuelta no es posible identificarla, pero sí reconocer su sabor, y es en este punto donde la experiencia de la mente (frente a la antigua experiencia pública del sacrificio) tiene un papel que jugar. ${ }^{54} \mathrm{~A}$ veces el fundamento se describe en términos puramente negativos, no es esto, no es aquello (neti neti), otras como una esencia omnividente, omnisciente y omnipresente. ${ }^{55}$ Las upaniṣad teístas (las más tardías) presentan el fundamento cósmico como un gobernante soberano, siendo en ocasiones identificado con Rudra: «Sostiene a todos los seres, ha hecho todos los mundos y los protege y los hará aparecer al final de los tiempos». ${ }^{56}$ Pero todavía se sigue haciendo referencia a la víctima del sacrificio original, que servirá de fundamento a la devoción. El principio abstracto se ha hecho concreto (ofrendas, rezos de petición, ritos del amanecer y del atardecer), lo incondicionado condicionado. El fundamento requiere de los cuidados de la devoción (bhakti), que predominará en las enciclopedias puránicas de la época clásica. Esa tendencia alcanzará su máxima expresión en la Bhagavadgītā, donde se expone un teísmo sin ambigüedades. Pero en el periodo védico todavía no se ha llegado a este punto. La liberación dependía del conocimiento y la autorrealización antes que de la fe y la devoción. Cualquier cosa que distrajera de la vida contemplativa se consideraba perniciosa.

$54 B U 2.4 .12$.

55 IU 8.

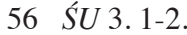


Algunos pasajes de las upanișad nos recuerdan que el universo surgió de un deseo primigenio y que el asceta debe reproducir ese anhelo en su mente: la autolimitación original (deseo de compañía, amor, si se quiere) que dio lugar al tiempo y sus manifestaciones.

\section{REFERENCIAS BIBLIOGRÁFICAS}

\section{FUENTES PRIMARIAS}

ĀNANDĀŚRAMA, Pandits of (eds.). 1980: Aitareyopanișad. Puna: Sanskrit Series. ĀNANDĀŚRAMA, Pandits of (eds.). 1915: Íśakenokațopanișadah. Puna: Sanskrit Series.

ĀNANDĀŚRAMA, Pandits of (eds.). 1935: Mundakopaniṣad. Puna: Sanskrit Series.

ĀNANDĀŚRAMA, Pandits of (eds.). 1977: Taittirīyopaniṣad. Puna: Sanskrit Series.

ĀNANDĀŚRAMA, Pandits of (eds.). 1980: Praśnopanișad. Puna: Sanskrit Series.

ĀNANDĀŚRAMA, Pandits of (eds.). 1980: Kenopanișad. Puna: Sanskrit Series.

BUITENEN, J. A. B. (ed. y trad.) 1962. Maittrāyaṇīya-upanișad. The Hague: Mouton.

GAMBHĪRĀNANDA (ed. y trad.). 1983. Chāndogya Upanișad. Calcutta: Advaita Ashrama.

MADHAVANANDA (ed. y trad.). 1982. The Brhadāranyaka Upanișad. Calcutta: Advaita Ashrama.

OLIVELLE, P. 1998. The Early Upanisads. Annotated Text and Translation. New York: Oxford University Press.

\section{FUENTES SECUNDARIAS}

BASHAM, A. 2009. El prodigio que fue India, trad. Jesús Aguado. Valencia: PreTextos.

BIARDEAU, M. y C. MALAMOUD 1976: Le sacrifice dans L'Inde ancienne. Paris: Presses Universitaires de France.

BLOOMFILED, M. 1908. The Religion of the Veda, New York.

DASGUPTA, S. 1992. A History of Indian Philosophy (vol. I). Delhi: Motilal Banarsidass.

EDGERTON, F. (trad.) 1944. The Bhagavad Gita Translated and Interpreted, 2 vols. Cambridge: Harvard Oriental Series.

ELIADE, M. 1997. El mito del eterno retorno, trad. Ricardo Anaya. Madrid: Alianza Editorial.

FATONE, V. Ensayos sobre hinduismo y budismo. Buenos Aires, Sudamericana. 
FRAUWALLNER, E. 1973. History of Indian Philosophy (vol. I). Delhi: Motilal Banarsidass.

GOMBRICH, R. 1975. «Ancient Indian Cosmology», en Ancient Cosmologies, Carmen Blacker y Michael Loewe (eds.), London, George Allen \& Unwin Ltd.

GONDA, J. 1975. Vedic Literature (Samhitās and Brāhmaṇas). Wiesbaden: Otto Harrassowitz.

GONDA, J. 1985. The Vision of the Vedic Poets. New Delhi: Munshiram Manoharlal.

GONZALEZ, L. 1988. Tiempo cíclico y eras del mundo en la India. México D.F.: El Colegio de México.

HASTINGS, J. (ed.) 1908. Enciclopaedia of Religion and Ethics. Edinburgh: T \& T Clark.

KEITH, A. B. 1925. The Religion and Philosophy of the Veda and Upanishads. Cambridge: Harvard University Press.

KEITH, A. B. 1928. History of Sanskrit Literature. Oxford.

KUIPER, F.B.J. 1983. «The Basic Concept of Vedic Religion» en Ancient Indian Cosmogony, John Irwin āed.), New Delhi, Vikas Publishing House.

MATILAL, B. K. 1986. Perception. An Essay on Classical Indian Theories of Knowledge. Oxford: Clarendon Press.

POTDAR, K.P. 1953. Sacrifice in the Rigveda. Bombay: Bharatiya Vidya Bhavan.

PUJOL, Ó. 2003. Diccionari Sànscrit-Català. Barcelona: Enciclopèdia Catalana.

PUJOL, Ó. y F. ILÁRRAZ 2004. La sabiduría del bosque. Antología de las Upanisads. Madrid: Trotta.

PUJOL, Ó. y A. DOMÍNGUEZ 2009. Patañjali / Spinoza. Valencia: Pre-Textos.

RADHAKRSHNAN, S. (trad.) 1968. The Principal Upanishads. London: Allen \& Unwin.

RAPPAPORT, R. 2001. Ritual y religión en la formación de la humanidad, trad. Sabino Perea. Madrid: Cambridge University Press.

RENOU, L. 1955-1965. Études védiques et Pāṇinées, 14 vols. Paris : E. de Boccard.

RENOU, L. 1968. Religions of Ancient India. New York: Sehocken Books.

RENOU, L y J. FILLIOZAT 1971. Vedic India. Indological Book House.

STAAL, F. 1982. The Science of Ritual. Poona: Bhandarkar Oriental Research Institute.

WINTERNITZ, M. 1972. History of Indian Literature, (vol. 1). Calcutta: University of Calcutta.

ZIMMER, H. 1951. Philosophies of India. Princeton: Princeton University Press.

JuAn Arnau (Valencia, 1968) es astrofísico y doctor en filosofía sánscrita. Además de traductor del sánscrito en trabajos relativos a Nāgārjuna, Fundamentos de la vía media y Abandono de la discusión (Siruela 2004 y 2006), ha trabajado las relaciones entre filosofía y traducción en Rendir el sentido (Pre-Textos 2008) y es autor de los ensayos La palabra frente al vacío, Arte de probar y Cosmologías de India (Fondo de Cultura Económica 2005, 2008 y 2012), Antro- 
pología del budismo (Kairós 2007) y Vasubandhu (Pre-Textos 2010). También ha ensayado el género narrativo en la Leyenda de Buda (Alianza 2011) y El cristal Spinoza (Pre-textos 2012). Actualmente es investigador de CSIC.

Dirección electrónica: arnaujuan@gmail.com 